\title{
Some reflections on defects in liquid crystals: From Amerio to Zannoni and beyond
}

\author{
Timothy J. Sluckin \\ Mathematical Sciences, University of Southampton \\ Highfield, Southampton SO17 1BJ, U.K. * \\ and \\ Dipartimento di Fisica, Politecnico di Milano, \\ Piazza Leonardo da Vinci 32, 20133 Milano, Italy \\ Submitted June 282018
}

Accepted July 112018

\begin{abstract}
Dedicated to Claudio Zannoni on the occasion of his 70th birthday.

I discuss some aspects of the history of dislocations, disclinations, and defects in liquid crystals, virtual and otherwise, placing Claudio Zannoni in the grand tradition of Italian science.
\end{abstract}

Key Words: Liquid Crystals; Zannoni; Defects;

Orcid ID: 0000-0002-9163-0061

Published in Liquid Crystals 2018, DOI: 10.1080/02678292.2018.1500652

*permanent address 


\section{Introduction}

In the summer of 1998, shortly after the death of Sir Charles Frank, David Dunmur, in his capacity as editor of Liquid Crystals Today, asked me to write a short biographical piece on Sir Charles, whom I had known slightly when I was a young scientist in Bristol. The effort of writing that article [1] led me into collaborative work with David and also Horst Stegemeyer on the history of liquid crystals $[2,3]$. I was thus, almost certainly, diverted from more serious scientific study. If I had doubts as to whether this was a sensible route, they were magnified when Epifanio Virga suggested to me at one of his quite excellent meetings in Cortona that I would fall, so to speak, between two stools, respected neither as a good historian nor as a good mathematician. But by then the die was cast, although I now fear that Virga was on the right track.

All this is by way of excuse for the fact that this article is more of a historical sketch than a serious scientific contribution. My first excuse is that the subject of these pages, Claudio Zannoni, is one of Italy's premier scientists, and that like serious scientists everywhere, he has a cultural hinterland which inspires interest not only in the intellectual roots of his own subject, but more generally in all aspects of the world around us, whether thought of in the Anglo-Saxon world as 'science' or 'humanities'. My second is that history has its own lessons, and is worthy of study in and of itself. It is a lesson upon which some of our political leaders (and I specify Italy, UK and US in particular here) might also do well to cogitate.

I shall discuss my own interaction with Sir Charles as well as some other personal matters directly apposite to my interaction with Claudio, toward the end of this article. In the bulk of this article, I want mainly to trace back some of the roots of our understanding of defects in liquid crystals, particularly in nematics. A subsidiary goal will be to place Claudio in the grand tradition of Italian science. In doing so, I will note specifically two early Italian liquid crystal pioneers, as well as spending some time with Vito Volterra, arguably Italy's greatest mathematician since the Middle Ages, and, as it happens, progenitor of the idea of dislocations.

While writing the two major pieces on the history of liquid crystals, I enjoyed an extensive correspondence with Jacques Friedel (1921-2014). One is always shy to approach the very distinguished, for fear either of wasting of their time, or of exposing one's own ignorance. But in this case I was encouraged by Maurice Kléman, who had been Friedel's graduate student. Friedel had known Charles Frank when he himself had been a graduate student in Bristol, had in the 1970s contributed personally to the theory of liquid crystal defects, and had later achieved greatness as the president of the French Academy of Sciences. For our purposes, of course, all this is for nought compared to the singular fact of his family pedigree: he was the grandson of the incomparable Georges Friedel (18651933). For those who may have forgotten, it was Georges Friedel who first understood the molecular organisation of the liquid crystal phases, and who baptised them as nematic, smectic and cholesteric, in his famous 1922 article [4].

Jacques Friedel's appreciation of our historical work was limited by what he felt (I paraphrase) was a major lacuna. We told of all the progress toward a molecular picture, and the key experiments, and all the different gadgets and devices and the relationship with fluids in living organisms, and so on and so forth. But he felt that we had omitted was the central place of structure in the disentanglement of the nature of liquid crystals. The key point is that until relatively recently (maybe the 1960s), (almost) all you could do with liquid crystals was to look at them, under a microscope, and with the aid of crossed polars, it should of course be added.

What you saw under the microscope were the liquid crystal textures. The origin of the 
word 'texture' is lost in history. When I say 'lost in history', I mean that $I$ have not been able to find definitively the first time it is used in its present-day context. By 1922, the term was well-established, because Georges Friedel uses it repeatedly in his classic work. The different liquid crystal phases were connected to the different textures. Sometimes more than one texture corresponded to a single phase, but if the phases were different, so were the textures. Your job as an experimentalist was to figure out what the texture told you about the phase.

Friedel was of course correct in his observation. The route from texture to phase is complicated. In the case of Georges Friedel, the road was facilitated by the rigorous mathematical training he received in the Ėcole Polytechnique, allowing him to make some serendipitous intellectual connections which would have escaped another less well educated in the classical arts. Indeed, it did escape his German competitors for precisely that reason. And, of course, those instructing the young Georges Friedel in the 1880s had no idea that their insights would be used in an entirely different field of science more than thirty years hence.

That route is somewhat more straightforward now as a result of the introduction of ideas from topology and homotopy into condensed matter physics in the 1970s [5-7] (see also the reviews $[8,9])$. That it is only somewhat straightforward attests to the fact that topology and homotopy are traditionally ideas from pure mathematics, associated originally with knots and the connectedness of space, by contrast with the usual fare of partial differential equations so beloved of applied mathematicians. I believe, but am not yet in a position to develop the idea, that there are interesting parallels to be drawn from the history of topology itself to that of the relationship of pattern to underlying structure in liquid crystals.

One day I would like to fill in the gap which Jacques Friedel pointed out. This article just touches the surface. For now, let me point out a few salient points. The first thing one notices, say about one string wrapped around another (an easier caricature of a knot) is how many times it is wrapped. Unless you move the whole wrapping rope to the end and untie it, the number of times you have wound around is conserved. In the trade it is known as a winding number, is easy to understand intuitively, and has direct application in a number of fields of theoretical physics. Charles Frank used the idea when thinking about liquid crystal defects, and so we shall return to it soon below.

There are somewhat analogous contexts in classical topology. The Italian mathematician Enrico Betti (1823-1892) introduced [10] a set of numbers which represented (sort of) the number of holes and handles in a space of dimension $d$ embedded in a nice simplyconnected space of dimension $(d+1)$. The numbers were later called Betti numbers by Poincaré in 1895, but are now regarded as surrogates for spaces of a particular type, and the so-called fundamental group which describes classes of continuous maps from the space of the surface to the embedding space (for a more comprehensive discussion, see [11]).

Analogously one could think about defects in a nematic liquid crystal in a similar way, and classify them using a winding number. As it turns out, the classification is incorrect, but it is not bad for a first attempt. We note the use of topology and homotopy in performing the difficult task of pattern analysis in liquid crystals, and muse whether there might be other pattern analysis contexts in which topology might be useful. Or is it only in the case of liquid crystals that data analysis is most efficiently performed by resorting to fancy pure mathematics? The answer, not surprisingly, is that no, liquid crystals are not special in this regard. Indeed, in all sorts of data analysis, particularly in high dimensions, topological ideas are turning out to be key in discerning pattern where intuition fails (see e.g. [12]).

This article is arranged as follows. I apologise to the reader for the higgledy-piggledy 
temporal order in which concepts are discussed, adopted for strictly utilitarian reasons. In $\S 2$, I recapitulate some of the early history of liquid crystals, treated more completely elsewhere. From a historical point of view, I might add that "more completely elsewhere" still means incompletely from an absolute point of view, at least in my opinion. An important element of this story concerns the Italian contribution to early liquid crystal history. In $\S 3$ I trace the development of the idea of a dislocation. This is crucial to our ideas of orientational defects in liquid crystals. Again the key ideas come from Italy, in this case from Vito Volterra.

Then in $\S 4$ I shall discuss Charles Frank. Material Scientists owe to Frank some of the key ideas in dislocations physics, and we in liquid crystals are the beneficiaries of the connections he made between these solid state ideas and defects in nematics. This and all subsequent sections include some of my own recollections, as well as some stories I have heard from colleagues. In $\S 5$, I try and connect these ideas with some more modern developments in understanding disclination structure in nematics. In $\S 6$ I pass to unashamedly personal recollections of how I entered the liquid crystal field and how I first came across Claudio Zannoni. Almost always I end my papers with a Conclusions section, and this is what I tell my Science Communication students in Milan they must do. But this paper is one in which I have to admit that there are no conclusions, although of course, all our careers conclude eventually, when the Grim Reaper decides, if not before.

\section{Some brief history}

I want here to repeat some brief history which is more throughly treated in books by myself and coworkers elsewhere $[2,3]$, as well as others who have taken slightly different points of view or emphaised different aspects of the same story [13-15]. The purpose is merely to make the present paper slightly more self-contained. Purists should note that the following is a caricature, so please don't quibble over detail.

Liquid crystals were first observed (or discovered, depending on your philosophical point of view) by the biochemist Friedrich Reinitzer (1858-1927) in Prague in 1888. Unable to make head or tail of his observations, he consulted the physicist Otto Lehmann (18551922) in Aachen. Lehmann had invented a powerful polarising microscope with a hot stage which was particuarly appropriate for studying these new materials. He named the materials 'liquid crystals', and made the subject his life's work. Most of his work was carried out in Karlsruhe, where he moved to in 1890, and spent the whole of the rest of his career.

More specifically Lehmann distinguished 'flowing crystals' and 'liquid crystals', the former corresponding to what we recognise as smectics, and the latter to nematics. His classification partly depended on the textures and partly on the fact that the flowing crystals were more viscous than the liquid crystals (and therefore flowed more slowly). Reinitzer had originally observed a cloudy phase interposed between crystalline and liquid phases. Many contemporaries focussed on the turbidity, posing a host of thermodynamic conjectures concerning the nature of the materials. A particular opponent of Lehmann's was the material scientist Gustav Tammann (1861-1938), who objected to the term 'liquid crystals' on the ground that it was a contradiction in terms and inconsistent with the (then unproven) lattice theory of crystals. Lehmann was able to show that the turbidity was the result of spatial inhomogeneity of the principal axis in an optically biaxial material.

In his optical polarisation studies of liquid crystal droplets, Lehmann often found pictures like that shown in Fig.1. He distinguished Kernpunkte (central points) and Konvergenzpunkte (convergence points), depending on whether the central dark region seemed circular or to possess 4-fold symmetry, and conjectured as to the principal axis configura- 


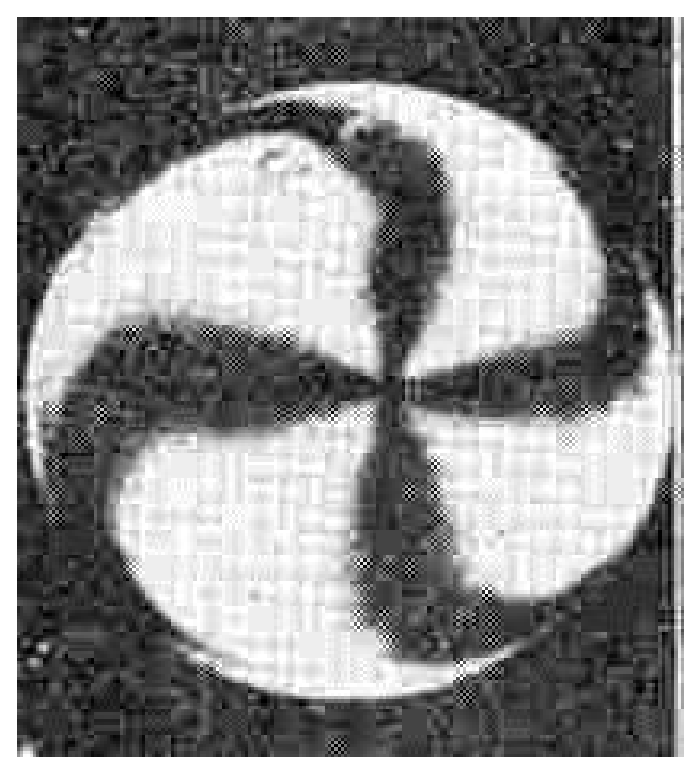

Figure 1: Liquid crystal droplet, as seen through Lehmann's microscope, taken from Lehmann's own work [16]. When the polarisers are rotated, the pattern also rotates, but the dark point at the centre remains fixed. The curved form of the brushes probably indicates that the liquid crystal in question was chiral.

tion which would be consistent with these observations. His 1904 book [16], which repays detailed reading even today, contains much else, in terms of details on his observational technique and the beautiful pictures he observed under his microscope.

As to an explanation for his observations, although Lehmann had a better idea than Reinitzer, he too was at a loss. Two interesting sets of observations have survived till the present day for explanation. The first concerns the shape of liquid crystalline droplets, which were not spherical as surface tension should have dictated them to be. Lehmann put the departure from sphericity down to Gestaltungskraft (directional force). In modern language this involves competition between anchoring and director elasticity, and is known as the tactoid shape problem. Real progress in this area had to wait until the 21st centuryi. There are comprehensive studies by Prinsen and van der Schoot $[17,18]$, and indeed it is a subject of contemporary research (see e.g. Zhang et. al. [19]).

A second set of interesting observations, also taken from Lehmann's book, is shown in Fig.2. The calculation of the full set of allowable configurations subject to a particular set of boundary conditions is obviously a formidable computational challenge, and in addition involves considerable topological insight. Current attempts in this direction can be found e.g. in Machon and Alexander [20].

Of particular interest to readers of the present volume is the fact that the first papers on liquid crystals not to be written in German were written in Italian. This was as early as 1901, and thus barely a decade after the first observations had been made. Claudio thus bears the weight of a long-standing tradition. One of the papers in question was written by the crystallographer and mineralogist Carlo Maria Viola (1855-1925). Viola [21] was trying to use crystallographic rules to investigate the crystalline structure of liquid crystals. The attempt was (of course!) unsuccessful, but he seems nevertheless to have succeeded in having a street named after him in Rome.

The second paper is more interesting, both in terms of its scientific content and the scientific pedigree involved. The author was Alessandro Amerio (1876-1965). I might mention that although Amerio was writing his liquid crystal paper from Florence, the 


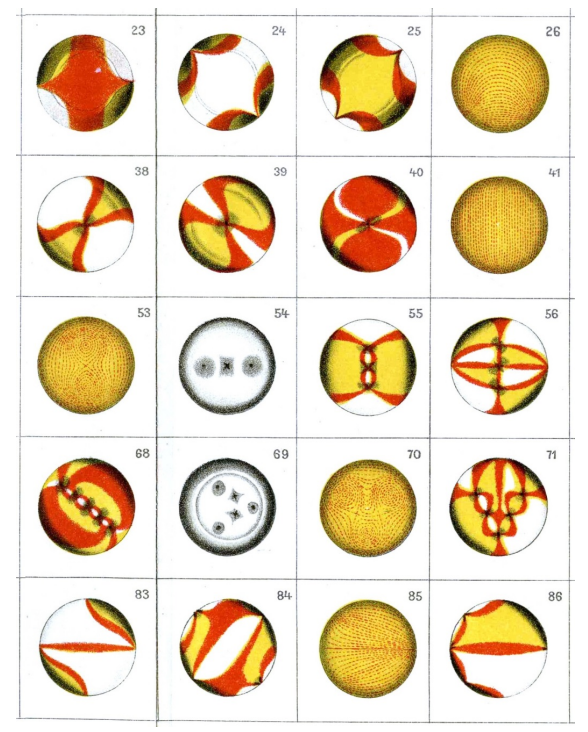

Figure 2: A portfolio of liquid crystal droplets, as seen through Lehmann's microscope, drwan from [16]. The colours are real, but added after the fact, as colour photography had not yet ben invented. The patterns obviously represent different configurations within the droplet, but the description of which configurations are permitted is a topic of current research.

bulk of his career was spent at the Politecnico di Milano, where his laboratory (now much celebrated) was located mere metres from where I am writing these words. Amerio's optical skills enabled him later to become perhaps the leading observational astronomer in Italy. His son Luigi Amerio (1912-2004), whose name is likewise linked indissolubly with the Politecnico di Milano, was a distinguished mathematician, known particularly for his work in quasi-periodic functions.

The title of Amerio's paper is Sui cristalli liquidi del Lehmann (On the liquid crystals of the Lehmann). Anglophone readers will find the article unnatural, but some other European languages are able to bestow eminence by the subtle insertion of a suitable article. In modern terminology, the key result of Amerio's work is that the transition between the liquid crystalline and liquid phases involves latent heat. Amerio is clear that something real is going on inside the materials over and above the fact that there is a change in appearance. His final section, entitled General observations: are the liquids crystalline or anisotropic?, gets to heart of the matter.

The contrast between anisotropic and crystalline liquids is interesting because Amerio, unlike his contemporaries at that stage, finds himself constrained to make a distinction between the two. Lehmann, by contrast, had in some sense bullied the German-speaking scientific community precisely into not drawing this distinction. Depending on one's viewpoint, at that time, one either thought of Lehmann as a madman or as a prophet. Amerio was thus on the right track, more than decade before Georges Friedel cracked the puzzle of the structural basis of liquid crystals. I speculate that had he been encouraged to continue, he might well have made major contributions. That he wasn't, is in part a function of the fact that he was writing in Italian, and hence would not be read by mainstream scientists, whether operating in German, French or English. There are some advantages 
to all scientific communications being in the same language, although it is not for me, as a native English speaker, to comment on which this language ought to be.

We pass onto the French contribution to the liquid crystal story. Lehmann had visited France and Switzerland in 1909 on an unashamed propaganda tour designed to interest his colleagues across the Rhine in his new materials. I would guess that part of his motivation involved the hope that the French would be more generous and more accepting of his ideas than his German colleagues. Georges Friedel, then at the School of Mines in St Étienne, and his younger colleague François Grandjean were only two of several to start work in liquid crystals. In his early studies, Friedel distinguished 'Liquides à noyaux' (or 'a fils') and 'Liquides à focaux', or to us 'liquids with centres/lines' and 'liquid with focal conics'.

It was only toward the end of the First World War (we are not sure when) that he realised that the focal conic and bâtonnet structures were consistent with grain boundaries in layered materials, while the centres (Lehmann's Kernpunkte) were points (or more usually lines) where the special liquid crystal direction was undefined. All these considerations were combined into book form [4] in what was actually a D.Sc. thesis (I translate into Anglo-Saxon terminology). The thesis gave him a degree which qualified him for a professorship at the University of Strasbourg, which had been returned to France at the end of the 1914-18 war. Interestingly the key basic term 'director' - despite the fact that the underlying concept is already implicit in all of Oseen's and Zocher's works in the 1930s - is much later and seems to derive from Frank Leslie in the 1960s.

Friedel was much rooted in experiment, which is what made him doubt Lehmann's directional forces, which he regarded as mysticism. In some sense he was right; the directional forces were ill-defined. The Swedish theorist Carl Wilhelm Oseen (1879-1944), the real creator of the continuum theory of liquid crystals, by contrast regarded an ill-defined experimental concept as a challenge rather than an illogicality (see e.g. [22]). Thus when explicitly asked by Oseen in 1930 what might be the molecular organisation in the 'fils' (i.e. in our language, on the defect line) in the nematic phase, Friedel replied that he had no idea and he certainly didn't have a mathematical formulation (see [2], p242).

I shall return below to this question, to which both I myself and Claudio have contributed somewhat, below. For the moment, we merely note at this stage there was no analogy with defects in solids. This is not least because the development of that theory did not reach an equivalent stage for another 16 years. It is to this subject that we turn in the next section.

\section{Vito Volterra and dislocations}

I anticipate slightly later parts of my story in order to justify my discussion of dislocation theory. In the late 1950s, Charles Frank coined terms for defects in nematic liquid crystals by drawing on analogy from the the theory of defects in solids. I want here to recapitulate some of this story, by returning to development of the theory of dislocations, whose roots are usually traced back to work by the distinguished Italian mathematician Vito Volterra (1860-1940) in the early years of the last century. Volterra himself is of sufficient interest that his intellectual story is worth a brief diversion.

\subsection{Volterra and Italian mathematics}

Vito Volterra (1860-1940) can justly be regarded as the most important Italian mathematician of the modern era. He has been the subject of numerous technical scientific biographies in Italian (see e.g. [23]) and one recent major biography concentrating on his human relationships [24] in English. This article concentrates on his foundational work 
in dislocations, but he was mathematician of many parts. In his early career he was the doctoral student of Enrico Betti, whom we have already mentioned in connection with the historical development of topology..

The polymathic nature of his abilities carries with it a less desirable side. Students of Volterra's mathematical papers rapidly observe the sheer power of his mathematical analysis. Much of his work is not easy going, not even for a professional mathematician a century or so forward from the time of writing. A further feature, which screens his work from our easy perusal, is the change in mathematical notation since that period. This change aids the intuition of the mathematically less able, although Volterra himself was not at all challenged by the heavy mathematical formalism of the day. Remarkably, however, when diverted to less technical matters, obituaries, for example, or essays on the current status of some scientific area, or technical reports for the government, Volterra's prose adjusts to the needs of its audience. The technical gobbledygook is gone and replaced by a model of clarity.

The mathematical sciences of the present day contain many references to Volterra's name. There are (different) Volterra processes in material science and in control theory, as well as Volterra integral equations and integro-differential equations in the theory of elastic media and indeed on the pages of every textbook on integral equations. The Lotka-Volterra equations appear almost on the first page of any contemporary treatise on theoretical ecology, sometimes disguised as the Volterra population equation. Elsewhere we find Volterra systems, Volterra series, Volterra operators, Volterra kernels, Volterra filters, Volterra spaces, and Volterra functionals. His astronomical work is celebrated by the the Volterra crater in the northern hemisphere of the far side of the moon. His name has even leaked out of the mathematical into the commercial world. For in London, Volterra Consulting will (presumably for a suitably gigantic fee, although I have to admit I have been too shy to ask) use mysterious quantitative methods to read the economic runes and help you thereby to run your company.

Not only were Volterra's professional contributions such as to place him in the scientific forefront, but as a scientist, he became a public figure. In 1905 he was elected a life member of the Italian Senate. He was elected a Foreign Member of the Royal Society of London as early as 1910. During the Great War of 1914-18, his war work took him to England (Italy was on the allied side in that war), and his organisational skills were used in balloon manufacture. In 1931 he was (and remains!) distinguished for being one of only 12 senators out of 1500 to have the courage to resist taking an oath of loyalty to Mussolini.

\subsection{Distorsions and dislocations}

Volterra's work often had profound but unintended consequences. One such concerns those discontinuities in crystal lattices which have come to be called dislocations. This work dates initially from 1905. As the reader will be aware, in 1905, neither the fact that most solids are built up from regular arrays of atoms (i.e. the lattice theory of crystals), nor the connection between the regular facets of observable crystals and the lattice theory of solids, had been established.

The definitive experiments proving the structure of crystals are due to von Laue and the Braggs, father and son, and in 1905 were still eight years into the future. Even the atomic nature of matter required Einstein's famous insight into Brownian motion, and Perrin's subsequent experiment, rather than the mere spatial imagination of chemists. And in any case, Volterra was a mathematician with interests in continuum mechanics. There is no record of him pursuing mechanics at molecular length scales.

Nevertheless, curiously, there is an intellectual route leading directly from Volterra's 
purely macroscopic studies of elastic continua, to the current profound understanding of the molecular properties of materials. The observational key to the transfer of Volterra's ideas from everyday to atomic length scales lay thirty years ahead. The puzzle concerned the flow of elastic solids when subject to extreme tension. In that sense Volterra's most enduring legacy to this kind of elasticity lay in the field of 'soft solids'. But at what point does a soft solid become a hard liquid? This is a question impossible to answer precisely. All we can say is that, in a sense, both of these contributions have been fruitful in the interregnum where the formal theory of elasticity has given out, but that of hydrodynamics does not yet hold sway.

But all this was far from Volterra's mind when, around 1904, he began to consider the properties of elastic materials in multiply-connected bodies. The echo between these studies and the pure mathematical considerations of Betti on how such mutiple connections can be classified will be clear.

The property of connectedness in a region of space is much considered by pure mathematicians and geometers. Let us briefly review the key ideas (I apologise to those already familiar!). A region is simply connected if any closed curve or surface inside it can be smoothly shrunk to a point. An example would be the inside of a sphere. A multiply connected region does not share this property. The simplest example is the inside of a donut (known as a torus to mathematicians). In this case a closed curve stretching around the axis of the donut is unshrinkable. The study and classification of such objects is known as topology. Topologists can divide all closed regions into classes, depending, roughly speaking, on how many holes or handles the region encompasses.

The initiating step in Volterra's study seems to have been a paper in 1901 [25] by the prominent, if rather elderly, German geometer Julius Weingarten (1836-1908). Weingarten at this time was in retirement from his job in Berlin and living in Freiburg-im-Breisgau, teaching part-time at the university, and (presumably) sharing its research ethos. He was a specialist in the geometric study of surfaces and his (rather short) paper was concerned with surfaces of discontinuity in elastic theory. Weingarten spotted that if the region was multiply connected something peculiar happens to elastic theory.

Weingarten published in an Italian journal because in 1899 he had been elected as a Foreign Member of the Accademia Lincei, the Italian equivalent of the Royal Society., and this paper was read in Rome when the award was bestowed upon him. Volterra's attention was drawn to Weingarten's paper. We know that he had some doubts over some of Weingarten's points. Moreover, Volterra realized that the four pages devoted to the subject by Weingarten were insufficient to do the subject justice. And thus started his researches in this area.

The peculiar elastic effect noticed by Weingarten concerned the internal state of stress and strain within a body. To understand Weingarten's point, we need first to ask what would not be peculiar. What is not peculiar (i.e. consistent with intuition) is that if we take a solid with free surfaces (and therefore subject to no external forces), then inside the body each macroscopic point will go to its favourite point, that the favourite point will be unique, and implicitly there will be no particle displacement. No displacement means no strain inside the body, and from elastic theory, no strain means no stress.

Now, if we put some forces on the outside of the body (i.e. external forces), then the elastic nature of the material transmits the forces to the inside of the body. The articulation of the forces inside the body is that the stress tensor is non-zero. Non-zero stresses imply non-zero strains, and non-zero strains can be integrated to determine the local (unique) local displacement. The story is clear and unambiguous. External forces imply displacements and vice-versa, whereas no external forces imply no displacements and vice-versa. 
But Weingarten found that if the body is multiply-connected this no longer holds. And once Weingarten had, so to speak, introduced a new ball into the game, Volterra picked it up and ran with it. What Weingarten found, and Volterra elaborated in great detail, was that a multiply connected body could sustain internal stresses and strains without any external force being applied.

Once one thinks about it, this is not so surprising. Volterra's explanation was a model of clarity. Consider a cylinder. A nice ordinary cylinder, with no holes in it, and thus no problems with connectedness. All particles in their proper places. Now, cut out a tiny hole along the axis. Not a big hole, only one just large enough for the body no longer to be simply connected. (In modern physics, we call this a short-range cut-off. It is a common trick in continuum mechanics nowadays, to avoid singularities in the continuum theory which are not there in an underlying molecular theory. But in Volterra's time, it was new. And if in doubt, it was fine to cut out a big hole, not a microscopically small one. )

But we are not done yet. There were no stresses and strains before, and all we have done is to cut out a hole in the middle. So still no stresses and strains, and still no displacements. But now Volterra does something new. Next he cuts out a small slice, all the way from the hole in the middle to the outside of the cylinder. Then he throws it away. Still no stresses, still no strains, still no displacement. And now he takes what is left, pulls it so that the cylinder is closed again (apart from the hole in the middle). And then he glues it together (see Fig. 3). Glues it so that no-one could know that he ever cut the material in the first place, glues it so that the elastic properties are the same everywhere, even along the join, glues it so that we don't realize that we were ever using glue. You can't do this in practise, of course, but this (at least to begin with) was a gedanken experiment, the type theorists do, the type that exists in the mind of the beholder.

Now what happens? There were some surface forces, when we were pulling the cylinder closed. But now we have glued the cylinder together. The external forces have gone; now there are only internal forces. But in order to close the cylinder, we had to move some points - in fact we probably had to move them all. So now we have a body with no external forces, but still it has internal stresses, internal strains and internal displacements, which depend, at least partly, on the way in which we glued the cylinder together.

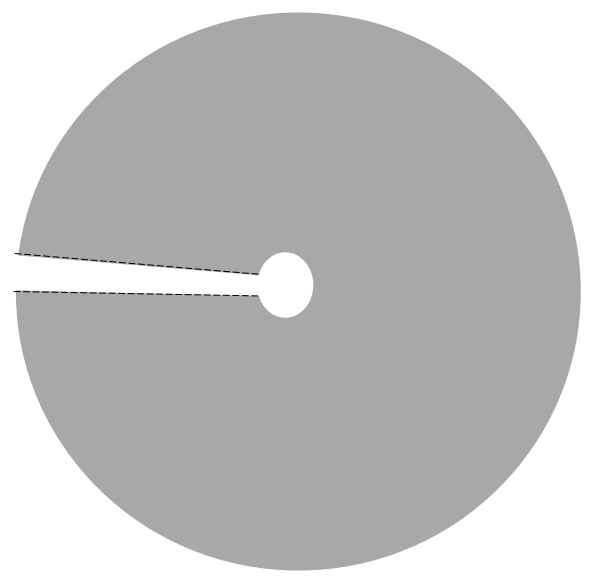

Figure 3: Example of a Volterra cut. The dotted lines are then glued together, leaving a multiply connected region.

So the peculiar elasticity is not so peculiar after all. The cuts and the gluing are like the constructions, so beloved of Euclid, introduced to help him demonstrate the truth of 
an apparently ridiculous hypothesis. You need them in the middle of the argument, but at the beginning and at the end they are superfluous. And this construction will in material science forever be associated with Volterra's name: it is the Volterra process; making a Volterra cut with a Volterra knife.

But then, on further examination, it turns out that the elasticity theory is peculiar. In usual elastic problems, if you integrate the strain from one point to another, you get the relative displacement of the points as a result of the stress field. And if you integrate the strain round a closed circuit, you get back to where you started, and (of course!) the relative displacement of a point with respect to itself is zero. But here, because of the way that the strain fields have been set up, if you integrate round a circuit which includes the hole, you don't get back to where you started. You get back to where you started, minus the initial displacement you made when you cut and glued.

And if you don't get back to where you started, either the displacement is not a unique solution of the equations (polydrome in Volterra's language), or the displacement field is discontinuous across a cut made somewhere from the hole to the outside. Either one, or the other (you can choose whichever you prefer; they are mathematically equivalent). But neither is quite what one expects in a well-behaved theory. Whenever you get this phenomenon, Volterra says you have una distorsione (in Italian) or une distorsion (in French).

It turned out that all this is not quite as unexpected as one might think, and follows from the mathematical analogies between field theories for fluids, solids and electromagnetism. If you invent a magnetic scalar potential you get something like this when you go round a circuit along a line of force. And in a fluid, you can get a state of constant flow in an annulus, even without forces to push the fluid, as pointed out by Lamb [26] in his classic book on hydrodynamics.

Volterra presented this work originally in Italian in the Proceedings of Accademia Lincei in a series of papers appearing in rapid succession in 1905 [27]. They were translated with little change into French [28] (and therefore accessible to a much wider readership) in 1907, and published, together with some new material, in the Annals of the École Normale Supérieure. The exposition is long and detailed. It is not helped by the fact that Volterra does not always use the modern suffix notation; this notation, employed by Einstein in his work on General Relativity, and by all modern workers in continuum mechanics, allows the genius of Volterra (or Rayleigh, Maxwell, etc.) to be reproduced by the merely talented.

The length of the exposition is also partly explained by the need to consider systematically different kinds of distortion, i.e. different ways of gluing together the cut after the material has been cut out. Each involves a different kind of solution for the internal stresses and strains. A diagram showing the different types of distortion (Volterra called them 'distortions of the $n^{\text {th }}$ order') can be found in Fig. 4, taken from the book on the subject started by Vito Volterra in 1938 [29], but only finished by his son Enrico in 1960. There were originally six non-trivially different types of distortion, though by clever argument, Volterra was able to prove the equivalence of some of these types.

Volterra was sufficiently excited by the possibilities inherent in his work that he encouraged a number of experimentalists to build apparatus to test his results. In the 1907 paper in French, he reports work by a Dr. Rolla, from the Physics Department at the University of Genoa. The internal strains would manifest themselves by optical anisotropy, and so a birefringence experiment should be able to detect them. Photographs of Rolla's apparatus ( $6 \mathrm{~cm}$ tall, $5 \mathrm{~cm}$ outer radius, $2 \mathrm{~cm}$ inner radius) are presented in the paper, and the theory is declared confirmed.

I leave aside some other details of the original papers in order to pursue the later history of the subject. The paper aroused considerable interest (partly perhaps a ripple 


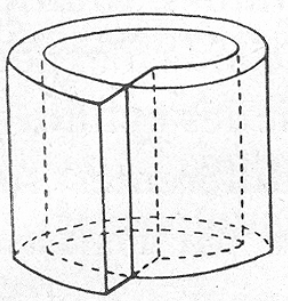

Distorsion d'Ordre 1

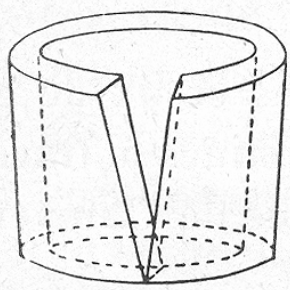

Distorsion d'Ordre 4

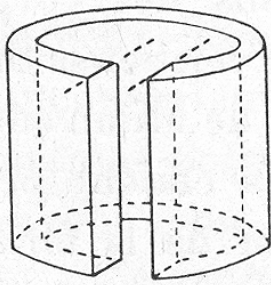

Distorsion d'Ordre 2

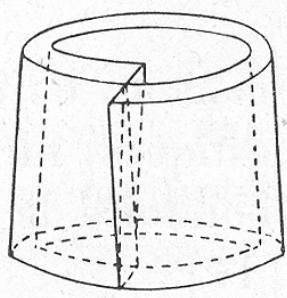

Distorsion d'Ordre 5

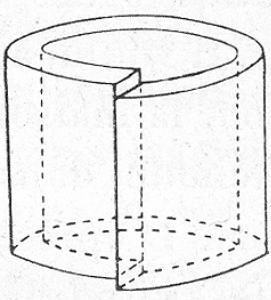

Distorsion d'Ordre 3

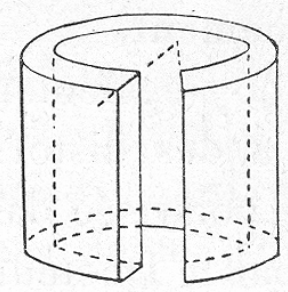

Distorsion d'Ordre 6

Figure 4: Distorsioni of orders 1 to 6 (from Volterra and Volterra [29]).

effect due to Volterra's own high prestige), and set off quite a little Italian cottage industry. Already the 1907 paper reports parallel work on the same subject in a 1905 Göttingen thesis by Timpe*. There were also papers by Cesàro, Maggi, Corbino, Trabacchi, as well as several by Colonnetti and Volterra's distinguished close colleague Carlo Somigliana.

Perhaps it was these papers, or perhaps, more likely, it was Volterra's visit to England in the course of war work in 1917 or 1918, that attracted the interest of the English mathematician A.E.H. Love to his distortions. Love, it will be recalled, was (perhaps one should rather say is) the author of the Great Standard Work on elasticity [30]. Love was in the process of revising his famous treatise. When the new edition finally appeared, in 1927, it included an entirely new section entitled "Volterra's theory of dislocations". Apparently arbitrarily, and with a light apology, Love, in his own words, "rendered (distorsioni) into English as dislocations". Why this apparently deliberate mistranslation? Perhaps it was that "distorsione" is the opposite of "torsione", and although there is a tor sion in English, there is only a distortion, which is not quite the contrary concept. But one thing we do know, which is that Love's book is replete with distortions of one sort or another. Perhaps this extra distortion would simply have been a twist too far. And, of course, for the liquid crystal world, the linguistic translocation is a happy one, for we (like Volterra's Italian colleague Alessandro Amerio) draw a real distinction between dislocation and distortion.

\subsection{Dislocation physics}

Whatever the reason for coining the new term, it stuck, and thenceforth dislocations it was. Now, the presence of one's own private section in Love's book is akin to the elevation to Olympus of an ordinary mortal. The work achieves biblical status, and with it the uncritical acclaim that goes with that status. And so, when in a different field with different antecedents, there was a coincidence of interests that required a renewed examination of the distorsioni, then the field of dislocation physics was born.

Dislocation physics, as we understand it, now almost a hundred years on, involves

${ }^{*}$ Folk-history tends to report this work as 1905, but Volterra's work as occurring only later in 1907, but Folk-historians tend not to read either Italian or German, and so Timpe's work tends to remain unread. 
microscopic scales and irregularities in the crystal lattice. The evidence, as opposed merely to the suspicion, that the fundamental particles in a crystal are arranged in a regular lattice, comes from X-ray scattering experiments [31,32] carried out in 1912-13.

For what it is worth, the suspicion is much older, and goes back, at least, to the French crystallographer René-Just Haüy (1743-1822)]. Likewise chemists, from Dalton onward, constructed a whole edifice of explanation requiring real molecular shapes, and hence real atoms, which also provided circumstantial evidence for the lattice theory of solids (for a discussion of some of these issues, see e.g. [33]).

Once the lattice structure had been established, it took some time for the implications to sink in. One question concerns the temperature at which the forces between the atoms are no longer strong enough to hold the lattice together. This would explain the melting temperature. A second question concerns how hard you have to pull in order for this to happen. This is the so-called yield stress $S$. A rough estimate, due to the Russian physicist Yacov Frenkel (1894-1952) [34], suggests that this should be of the order of the elastic modulus, which is itself the ratio of the stress to the strain (a stress has the dimensions of pressure $=$ force per unit area). If the strain is of order unity, then atoms are roughly twice as far apart as they should be, and at twice as far apart, so the argument goes, the crystal should fall apart. And although when this is the case, the stress will no longer be responding linearly to the strain, the linear rule should give an order of magnitude estimate.

It soon became clear that this estimate for the yield strength in metals was way too high, perhaps by two orders of magnitude or more. The Frenkel estimate (technically of the theoretical shear limit, which occurs when you try to set the crystal into shear flow, rather than pull it apart by brute force, but the idea is the same). A shear field in a solid creates stresses which in a fluid would cause shear flow, but in a solid usually only cause a shear distortion. This distortion involves the first stage of slicing a material apart.

Now some materials are easily sheared apart but only yield under tension with difficulty. In other materials it is exactly the opposite. The estimate could be out by a considerable factor and still not perturb our theoretical understanding, precisely because it is just an estimate. But not more than two orders of magnitude wrong. The naïve picture of crystal breakdown, in which the lattice is literally torn apart, must be wrong. This observation was coupled with a further observation that when the crystal did slide, it did so not smoothly, but in a series of little jumps.

Speculations as to why this might be were made in 1929 by the German theoretical physicist Ulrich Dehlinger (1901-83) [35]. Dehlinger realized that in a shear field one layer of the crystal must slide by the next, periodically getting stuck when the crystal is wellordered. He pictured this in terms of little hooks (Verhakungen) on one crystal plane which grabbed hold of the next plane, only to let go again when the sliding force became large enough again. But the real puzzle was why the shear force must be concentrated in some places in such a way that it could yield locally, and hence globally by a series of little slips.

The key idea was presented in three almost simultaneous papers in 1934 by the English physicist G.I. Taylor (1886-1975) [36], and the Hungarian chemists Egon Orowan (190189) [37] and Michael Polanyi (1891-1976) [38]. In Material Science, the story so far is regarded as the prehistory of dislocations. The history, as properly understood, starts with Taylor (later Sir Geoffrey, and the doyen of British fluid mechanics), Orowan (who later emigrated to the U.K., and then in 1950 to the U.S., subsequently finishing his career at M.I.T.) and Polanyi (who in 1934 had just arrived in Manchester, and later had a distinguished career as a philosopher of science). All three contributions identified irregularities in the crystal lattice as the fundamental elements of the solution. 
The idea was that inside a crystal there are regions where the lattice changes its point of reference. All three papers identify lines along which an extra row of atoms is introduced into the lattice, shown in Fig. 5.

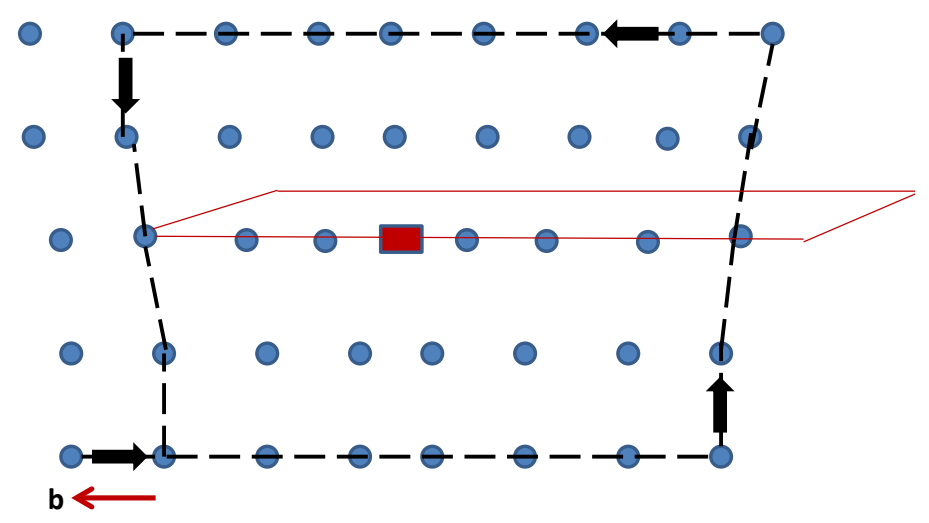

Figure 5: An edge dislocation, showing the Burgers circuit and Burgers vector $\mathbf{b}$, the glide plane, and the extra plane of atoms above the dislocation. Atoms are blue circles, and the dislocation itself is shown as a red square. The edge dislocation corresponds to a distorsione of order 6 in Fig. 4. The Burgers vector and circuit is discussed in more detail in Section 4 below.

So now, in most of the crystal the lattice is regular and well-behaved, apart, maybe, from a little strain, which you detect by a departure of the regular crystal cell from its proper shape. In this case you take a circuit in the lattice: $n$ atoms to the left, $m$ atoms up, $n$ atoms to the right, and finally $m$ atoms down again. Where do you finish up? Back where you started, of course.

But if your circuit contains the line where you have added the extra row of atoms, you don't finish up where you started. You finish up one atom to the right. G.I. Taylor recognized what was going on; he knew his Love, he was familiar with the new section on Volterra's dislocations, and in any case he had met Volterra during the first world war. Taylor, unlike Polanyi and Orowan, cited Volterra, explaining that Volterra's mathematics held the key to understanding these new objects.

The full microscopic mathematical formalism was provided by the Dutch theoretical physicist Johannes Martinus Burgers (1895-1981) [39,40]. Burgers borrowed copiously (as he openly recorded in later life to those who might have mistaken - indeed, did mistake - the required mathematical virtuosity for his own). The key element in mapping the Volterra theory onto the molecular problem is the cutting-out process. Because the lattice must match everywhere away from the dislocation line, only certain kinds of cuts can be made before the Volterra gluing begins.

There are different kinds of possible processes, corresponding to Volterra's distorsioni of different order, or associated with different vectors which occur on making a circuit. Thus we get different kinds of dislocation - the edge dislocation is the one appearing in Taylor's seminal 1934 paper, whereas Burgers also introduced the screw dislocation, in which the vector shift on one circuit is parallel to the dislocation line.

And then, almost within the blink of an eye, dislocations were everywhere in material science. They explain work-hardening, in which the yield strength increases after bashing the material around a bit, because (roughly speaking) the dislocations become entangled, and the crystal lattice gets stuck. And they explain crystal growth from the melt [41], 
because the there is always a spare misaligned layer at the crystal-melt interface for the new atoms to attach to. Then it was realized that some old puzzling micrographs by Menzies and Sloat [42] could easily be understood in terms of dislocations; they were staring us literally in the eye, but we couldn't see.

Nowadays, the study of dislocations is a central part of all undergraduate materials science courses, leaking out into physics as well. All the standard textbooks, at least all those who dare subject their readers to more than Mickey Mouse mathematics, lean heavily on the treatment provided by Volterra to the readers of the Annales de l'École Normale Supérieure. In geophysics too, the study of dislocation stress fields is central to the understanding of earthquake genesis and dynamics.

And what of Volterra's original distorsioni? Burgers's application of Volterra's theory came just too late for Volterra to have a chance of perusing it (or indeed, pursuing it) in his lifetime. Perhaps these new microscopic distorsioni would have excited his imagination in new directions. In their book on the subject [29], Enrico Volterra is in two minds. On the one hand it is clear that he shares some of what would have been his father's pride at the extensive application of his ideas in this new scientific area. On the other hand these are no longer their distortions, but something else. Enrico is more interested in other applications, particularly in his own speciality of civil engineering. Arches, he points out, are primitive examples of non-simply connected structures which are maintained in a state of stress without external forces. The well-known stability of arches is a consequence just of distortion theory.

But whether there are extensive applications or not of the dislocation ideas in their original form, it is in their new microscopic guise that the concept has blossomed and flourished. It is yet another example of how good ideas in science can be used opportunistically and unexpectedly to build a better overall understanding of the world in which we live.

\section{Sir Charles Frank and disclinations}

It was Charles Frank who, in an article published in 1951 entitled 'Crystal dislocations: Elementary concepts and definitions' [43] finally drew the various ideas together. Fig.5 shows a circuit around the crystal defect line consisting of $n$ steps up and down, and $m$ steps to the left and right. The anomalous nature of the crystal defect is articulated in the fact that one does not return to the original position, and an extra vector $\mathbf{b}$ is required to close the circuit. It was this vector (which had rather been defined by a triad of lattice steps by Burgers) which Frank labelled as the Burgers vector.

Frank was extremely well-known in the material science field. Jacques Friedel in his memoirs [44] went so far as to claim that so high was the quality of his work that he had been unjustly denied a Nobel PrIze. Space prevents us from exploring his career in this area. From his interest in hard solids came also an interest in softer solids (the Bristol polymer group was a fruit of this interest), and hence also in liquid crystals.

In 1958 Frank was invited to introduce a Faraday Discussion meeting in Leeds on liquid crystals and macromolecular systems. The resulting article [45] recapitulated points made by Oseen in a similar Discussion Meeting in London in 1933. The article sets out, with Frank's usual clarity, his view of the continuum theory of liquid crystals. This was essentially invented by Oseen in the 1920s (see e.g. [22]), but not completed until Frank Leslie's formulation of the Ericksen-Leslie theory in 1968 [46]. It also, significantly for our purpose here, adumbrated types of nematic defect, as shown in Fig. 6.

Frank's nomenclature of 'disinclination' was a deliberate analogy with dislocation. For just as a dislocation involved going round a circuit and finding oneself, as it were, 


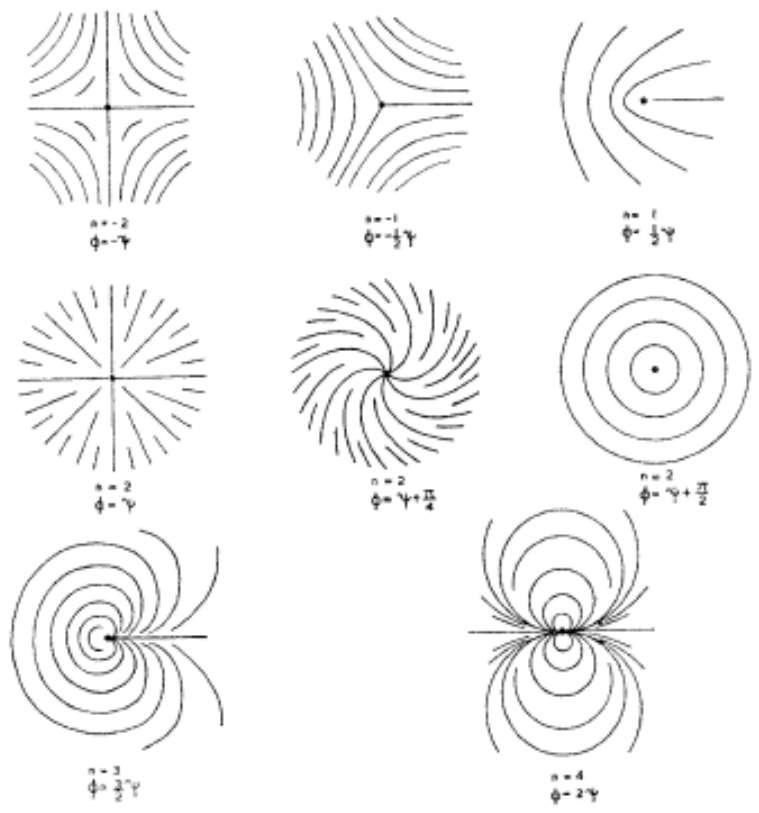

Figure 6: Frank's sketches of nematic liquid crystal defect lines (from [45]), labelled by winding number. He drew an immediate analogy between what he called 'disinclinations' and the dislocation theories which he had been developing in the decade preceding his famous 1958 paper.

somewhere else, likewise Frank thought of a disinclination as going round a circuit and finding oneself pointing, at least in some sense, "somewhere else". With the benefit of hindsight, we can notice what we might think of as 'folk homology'. Frank correctly notices that some disinclinations can be distorted into others (are we not glad that Love abolished distortion from the solid defect literature!), his classification is incomplete because actually all index $\pm \frac{1}{2}$ defect lines are equivalent, in the sense that they can be deformed into each other.

I have told the curious tale of the linguistic distortion of the disinclinations elsewhere [1], but it is sufficently amusing that it bears repetition. In 1969, Jacques Friedel and Pierre-Gilles De Gennes (what a powerful combination!) published a paper in the Comptes Rendus de I'Académie des Sciences entitled Boucles de Disclination dans les Cristaux Liquides' (Disclination loops in liquid crystals). Well, the article was in French, there is no translation of the neologism 'disinclination', so maybe this was just a piece of imaginative translation. But at roughly the same time an article in the Journal de Physique from the Orsay Liquid Crystal Group (these were revolutionary times, remember, and to avoid the cult of personality we all publish under a group pseudonym) [47], was referring to dèsinclinaisons. But in the very next paper in the same journal Kléman and Friedel [48] were referring to disinclinaisons. The following year, Kléman, this time in collaboration with Yves Bouligand [49] in the same journal, and again publishing in French, was still referring to disinclinaisons. But now he was constrained to provide an abstract also in English, and his English translation is.... 'disclination'. And disclination it seems to have remained. Some time ago, I asked Maurice Kléman about this important terminological question. He thought for a moment, searched back long in his memory, hummed and hawed a bit, finally dredging up an uncertain:

"I think it was de Gennes who said he was disinclined to be disinclined." 


\section{Some more modern developments, including some con- cerning the Zannoni group}

I want to pass to more recent developments which involve defects in nematic liquid crystals. My main topic here concerns defect cores in nematic liquid crystals, specifically point defects. However, I note that the Bologna group has also made significant progress in understanding liquid crystals in porous media. It turns out that such media, at sufficiently low temperatures, are threaded through with frozen disclination lines [50-54] which destroy the long-range order and seem to govern all sorts of macroscopic properties. As I have a competing (if somewhat similar) model $[55,56]$, I am particularly interested to know whether there is a simple mapping between the two pictures. It is of some serendipitous interest that these porpous media seem to be the only systems which actually stabilise, from a thermodynamic point of view, nematic disclination lines. However, the ubiquity of the disclination lines is apparent, not only from the pictures taken between crossed polars, but because of the turbidity of the nematic phase (although this may also be a thermal fluctuation effect).

I first give some cultural background. As is well-known, there are two key static theories of nematic liquid crystals at length scales larger than the molecular. The continuum version is that due to Oseen (see e.g. [22]), as rephrased by Frank [45]. This uses the director $\hat{n}$ as the key quantity. The other is due to de Gennes [57], and is in the spirit of Landau, and is a kind of mesoscopic theory apprpriate on scales between the molecular and the macroscopic. This expresses the free energy in terms of what we now call the Q-tensor $Q_{i j}$ (and what de Gennes called the Saupe ordering matrix).

They must in some sense (where we leave the meaning of in some sense fluid!) be equivalent. In recent years real mathematicians have been busy going from Frank to de Gennes, taking limits (correctly) in a manner only analysts can, and normal human beings (the present author claiming for the present purposes to be in the latter category) cannot (see e.g. [58] for a more complete description). Nevertheless in the early 1980s with my post-doctoral colleague Poniewierski, I was foolish enough to attempt to construct a procedure which passed from one model to the other [59]. Our paper contains a mathematical blunder, rapidly (and tactfully!) pointed out by Lech Longa and Rainer Trebin [60], who in any case approached the problem from a more sophisticated mathematical angle. A corollary of our approach was the identification of extra terms in the free energy of a uniaxial nematic which coupled to biaxiality, and in particular induced biaxiality in a non-uniform nematic.

Eager to demonstrate that our approach was not mere head-in-the-clouds-theorism, we sought an example where inhomogeneity was obligatory. The obvious example was a disclination line. The final section of our paper was thus devoted to calculating the induced biaxiality in the outer reaches, so to speak, of a wedge disclination, using a perturbation theory starting with the Frank solution. The inner core, where everything went haywire, was obviously outside the perturbation limit, and (like Georges Friedel, of whom I had at that time not heard) I expressed no opinion. The natural language, it seemd to me to describe the departure of the Q-tensor from its uniaxial form seemed to me to be a magnitude, and a set of directions, i.e.

$$
Q_{i j}=\frac{1}{2} S\left(3 n_{i} n_{j}-\delta_{i j}\right)+B\left(l_{i} l_{j}-m_{i} m_{j}\right)
$$

where $S$ is the nematic order parameter we know and love, $\hat{n}$ the director calculated in the usual way neglecting any biaxiality, and the newer quantities $B$ is the degree of biaxiality, and $\hat{l}, \hat{m}=\hat{n} \times \hat{l}$ are now the principal axes defining the biaxiality. So the question was, what happened to the biaxial markers as one approached the disclination line? 
The further question of what happens inside the core of the disclination was too complicated, not least because once we get there, the nematic director $\hat{n}$ is no longer defined. It was only after I arrived for a sabbatical period in Grenoble in early 1987 and started to talk to Nils Schopohl that the next step became obvious. Schopohl had experience in superconductivity, but none in liquid crystals. He could also write code much better than me. And he asked why I had to use the biaxiality and not the fundamental Q-tensor to do the calculations. I explained that my intuition worked in biaxiality but not with the Q-tensor (it wasn't a 'Q-tensor' yet, but never mind). Schopohl suggested that maybe it was my intuition that was lacking and not the mathematics. So we began to calculate, using the Landau-de Gennes approach, expressing our results for the disclination core in terms of energy densities and Q-tensor eigenvalues, rather than degrees of biaxiality.

In the end we published two papers on this work. One dealt with disclination lines [61]. There had been speculations that the core might be isotropic, and our results suggested that while this was sort of right, in detail it wasn't, and inside the core the Q-tensor had two positive eigenvalues and one negative (as opposed to in the bulk, where it was two negative and one positive). The core line could be identified with a line on which the two positive eigenvalues were equal, and the core region was bounded by a tube along which one eigenvalue of $\mathrm{Q}$ is zero (also see [62] for a mathematical proof of this statement, my only paper with a proof in it!).

The second paper concerned the structure of the hedgehog point defect [63]. We placed the hedgehog inside a sphere with radial boundary conditions. My three-dimensional intuition (i.e. closing my eyes and looking: my version of homotopy) was that there would be a disclination ring somewhere, thus breaking the spherical symmetry. But try as we might, the spherical symmetry remained uncompromisingly firm. Even when relaxing the solution from an initial ring-like configuration, the ring dissolved leaving not even the grin of Cheshire cat. So eventually we gave up, and solved a (much easier) radial equation instead. To compensate for the lack of disclination ring, we investigated magnetic hedgehogs and found a difference in the power law behaviour of the order parameter near the origin. Once again it was Trebin [64] who was able to show that at least under some circumstances we must have been in error. I was more than a little disappointed. Interestingly, it was only more than a decade later that Mkaddem and Gartland [65] showed that both configurations are possible. Perhaps we made no specific computational error, other than look in the wrong part of phase space.

Let me now pass to computer simulation checks of these results using more microscopic models. In 1993 Hudson and Larsen [66] studied a line defect of a hard-particle liquid crystal, using the Monte Carlo method, and found a structure consistent with that we predicted. Somewhat earlier I was able to obtain funds for a joint project with Claudio's group to investigate the structure of the nematic hedgehog. We used the Lebwohl-Lasher lattice model. The interesting result [67], from my point of view, was that if one took a spherical average over all configurations, our 1988 result was confirmed, but that a detailed examination of the instantaneous configuration, it was clear that the symmetry was broken and there was indeed a defect ring, as expected from Trebin's work [64].

At about that time the subject took off somewhat. In 2000, Claudio and colleagues organised an meeting in Erice entitled 'Defects in liquid crystals, computer simulations, theory and experiments', the contents of which were published as a book [68]. Among many interesting articles were several reports from the Bologna group simulating defect properties and behaviour [69]. The subject has attracted further interest because of the interactions between point defects in a nematic colloid and the colloidal particles themselves (see e.g. [70]), and the existence of knotted disclinations acting a kind of glue holding colloidal particles together in this context. Unfortunately, we cannot do justice to recent 
progress, save to observe that the Bologna group has been very active [71-75]. As a final postscript, given the renewed interest in biaxial liquid crystals [76] we mention very recent work from the Bologna group on the structure of droplets of nematics which consist of molecularly biaxial particles [77] . This shows that the core size seems to increase as a function of the biaxiality of the molecules, although the precise implicaitons of this are not clear at the moment.

\section{Personal matters}

I first came across the name 'Claudio Zannoni' several years before we met. The story is somewhat contorted and bears retelling. Between 1978 and 1981 I was a postdoctoral fellow with Bob Evans in the physics department at the University of Bristol. The project involved calculating structure factors in simple liquids consisting of spherical molecules. We were using the perturbation theory which had relatively recently been developed by Weeks, Chandler and Anderson [78]. The structure factors in question were calculated using the direct correlation function, an at first rather mysterious quantity first posited on heuristic grounds in 1914 by Ornstein and Zernike [79]. It turns out that the mysterious and difficult-to-calculate direct correlation functions are functional derivatives of the free energy, a mathematical relation which much impressed the interviewing panel when I came some years later to be interviewed in the Mathematics Department at the University of Southampton. In reciprocal space, they are also, more or less, functional inverses of the observable structure factor.

My part in the calculation involved some rather heavy computing, which in those days, meant spending long hours into the night printing large number of punched cards. The previous postdoc on the project had departed for Germany, leaving some code which didn't work unless you applied some kind of fix. It was something to do with convergence, and I knew that we were going to consider binary fluids, I rewrote the code to include the general case of an $n$-component fluid, and optimistically sent the cards off for processing. Older (er... more senior) colleagues will remember the card-writing and card-reading machines, which were not $100 \%$ reliable. The idea was that the computer compiled your cards, gave you a printout, as well as a a traceback to the bug in your code. As it turned out, the creator of the cards was much less than $100 \%$ reliable as well.

The first night my code didn't work. Nor did it work after a week, nor after a month, and truth to tell, nor after a year. There wasn't an established method to explain what I was doing wrong, and, well, I have to admit that probably it was in some considerable degree my lack of talent. I know now, I tell all my students and junior colleagues. You start with a simple program and make it work. Then you complicate. Your code may be ugly and not optimised, but you'll get there. All this printing out, and running between buildings and having to work in the middle of the night surely didn't help. But my biggest error was that of the theoretician and specifically, that of the mathematician. I tried to make the particular a special case of the general, whereas I should have generalised the particular.

The result of my failure was that my mind wandered. Moments of the direct correlation function yielded the coefficient of the gradient-squared term (i.e. of the $\left.(\nabla \rho)^{2}\right)$ in a free energy description of an inhomogeneous fluid. The then 22-year-old Margarida Telo da Gama, who was Bob Evans's new graduate student (I think I have remembered this right), was using this to calculate surface tensions in terms of molecular parameters. So I became interested in surface properties, first of ionic fluids, and then of simple fluids consisting of diatomic molecules.

The specific motor of my interest in molecular fluids (I have told part of this story 
before in the pages of 'Liquid Crystals') was the arrival, some time in early 1979, of two new books in the Bristol physics library. The books were brightly-coloured, hard-backed and large-sized.

The first of the books was yellow and was entitled The Physics of Liquid Crystals and was by Pierre-Gilles de Gennes [80], whose work in magnetism I was already familiar with. The second was light green, was wrapped in cellophane, and was entitled The molecular physics of liquid crystals. It turned out to be an edited compendium of tutorial papers by two chemists with whose names I was not at all familiar: G.R. Luckhurst of the University of Southampton and G.W. Gray of the University of Hull [81].

The paper of both books was smooth and virginal. Also, and I am sure that this was a contributory factor, given that I had (by now...) abjured stronger stuff, they smelt great. The misadventures in the project that was paying me allowed me to give myself permission to explore. From them I learnt about the basics of liquid crystal physics. I know that the Luckhurst-Gray book was the edited proceedings of a 1977 summer school in Cambridge and that many of the participants were scarcely older than me. But somehow I missed it in the search for an order parameter which would describe the surface order in the molecular fluids.

I wanted to know whether the Nitrogen or Oxygen molecules would stick up at the surface, or lie flat. Chapter 3 of the Luckhurst-Gray book had a long and detailed chapter on liquid crystalline order parameters by an obviously distinguished and mature scientist by the name of Zannoni [82]. de Gennes told me about what he called the Saupe ordering matrix, and Zannoni's chapter gave a more comprehensive exposition.

I will omit what happened to my doomed computer code, and also the details of molecular ordering at the surface of simple molecular fluids, which readers can look up themselves. They may, however, also be interested in another personal detail. The Bristol theoretical physics group had a powerful pedigree. Between 1933 and 1954 the guiding spirit had been N.F. Mott, and in the late 1940s one of his research students had been Jacques Friedel. The head of department at the time I was there was J.M. Ziman, whose work in solid state physics had been legendary, but who at the time was begining to move toward the sociology of science. Mott had hired Charles Frank, following his distinguished war work. It was an amzing hire, and Frank went on to an extremely distinguished career in material science with (as we have seen) contributions in particular to dislocations in solids, although actually he was a polymath. Of the members of the solid state group when I was there, the Hungarian emigré Balazs Györffy was a one of the leading band theorists in the UK, Bob Evans was later to become FRS for his work in liquid-state physics, while Michael Berry (first FRS and then also knighted) is known the world over for his work on optical structures.

At the time I arrived (in September 1978), Frank had recently retired. By reputation he was a daunting intellectual figure, and one who did not suffer fools gladly. I have to say that in all my interactions with him, he was nothing but polite and not in the least frightening. On his retirement, he had been relegated to a small office just across the corridor from that which I shared with two other postdocs. I am not known as a shrinking violet, but I have to report that the boom of Sir Charles's voice reached from one end of a very long corrridor to the other. He had a slight limp, and seemed very old; very very old. It is with some shame that I can report that at the time of my arrival in Bristol he was actually almost exactly the same age as I am now.

Sir Charles seemed to be a figure from another era. His only teaching work involved final year projects, in which the student had to discuss/interpret/translate papers from French or German. His German dated from his time as a postdoc, just before the war, in the laboratory of Peter Debye in Berlin. Indeed his first (somewhat unsuccessful) liquid 
crystal paper is in German and dates from that period [83]. He would accompany the other members of the group to lunch. It was not only the volume of his utterances which struck one. His clipped upper class tones are now almost extinct and the pipe on which he ostentatiously and continuously sucked would now be forbidden. And there was an interesting asymmetry in the form of his interaction with colleagues. They addressed him as 'Charles', by his first name, as they did each other, for anything else would have been unnatural, and 'Sir Charles' would have been excessively unctuous. But Sir Charles grew up in a period in which first name address implied great intimacy. In his youth one addressed one's peers by their surnames. To use a prefix: 'Mr.', 'Dr.' and so forth, indicated a degree of distance. And so it remained; his juniors using their customary form of intimate address, and he, while not objecting formally, indicating their status by the use of surnames.

I will fast forward to my appointment in the Mathematics Department in Southampton. At my interview in June 1981, they had asked me whether there would be anyone in the university outside Mathematics with whom I could collaborate. Spurred by the Beautiful Big Green Book (BBBG), I mentioned Geoffrey Luckhurst in Chemistry. For various reasons, some good, some not so good, it took several months for me to make contact with Geoffrey. As a point of interest, in early 1982 there had been a copy of the BBBG in the Southampton University library, but when a year or so later, I wanted to consult it, I found that someone had stolen it! In our day, when copyright law seems fluid and everyone is consulting a site-that-cannot-be named in Central Asia, even the idea of stealing a book seems rather unlikely. When in 2011, there was outbreak of rioting in London and a shopping centre was first looted and then burnt down, the one venue left untouched by the stuff-luvvin yoof was, yes you guessed it, the bookshop.

I hadn't quite realised that Claudio was an alumnus of the Luckhurst group. Geoffrey's tutoring has spawned a good number of professors in universities across the world. But my first awareness that Claudio was one of us came from an unlikely source. In the early 1980s British politics was in ferment. The Labour Party had lost the British general election in 1979, and been replaced by Mrs Thatcher's Conservatives. As we all know Mrs $\mathrm{T}$ was a tough cookie, and she was shifting Britian to the right. Many of the unspoken assumptions of the British post-war political consensus were changing. In reaction to this, for some reason that I don't quite understand, but as it is a repeating fashion, leftists across the world obviously do, there was pressure to push the Labour party leadership further to the left, as this was obviously what the people wanted.

I used to hang around in political circles. I was a 'right-wing' rebel in the Labour Party, and joined the newly-formed - and eventually ill-fated - centrist Social Democratic Party. But friends of mine remained members of the Labour Party. At a social event (i think this would have been in the summer of 1982), I met a young man called John Denham, who was an up-and-coming Labour party politician, and who had just been adopted as the Labour Party candidate for the neighbouring Southampton Itchen constituency (i.e. parliamentary district). We were discussing politics (or rather not discussing, because the social implications of the rift in the Labour Party at that time rivalled the current Brexit-induced animosity).

So it was with some surprise that I learned that he too had been a post-graduate student of Geoffrey's, but had withdrawn without obtaining a Ph.D. It did seem that his mind was still returning to liquid crystal problems (although truth to tell, not with great facility). I was still dead keen on science, and somewhat curious. Why, I asked, had he stopped doing science? The Luckhurst group was such a great place to work, and a leading lab in the world. Why on earth? Well, he explained somewhat sadly, there was another contemporary graduate student, an Italian called Claudio Zannoni. Apparently Claudio 
was so much smarter than John that he felt that he could not compete. He wanted to excel, but Claudio just eclipsed him. And rather than take second place, he changed subject.

As a politician, John Denham had a somewhat slow start. In the 1983 election he was placed third behind two other candidates. By the time another election came along in 1987 he managed to improve to second. In the meantime, he was active in local politics as a councillor. Finally in 1992, he was elected to parliament, a mere $1 \%$ ahead of the previous member of parliament. He had an extremely successful career, including a spell as the minister in charge of the universities, and achieved high cabinet rank.

Sometime around this time, Claudio actually came to visit in Southampton, and Geoffrey sent him over to my rather small office in maths. I must have discussed my direct correlation functions. I have to admit I underestimated the power of computer simulation, as a route to understanding, as opposed to a brute force method of checking what was going on. By the time I went on leave to France in the spring and summer of 1985, I knew Claudio well enough to visit Bologna. I came again in 1988, again from France, and in the early 1990 set up a project to study the internal structure of disclinations.

The contents of the rest of this article should convince you that Claudio will be remembered as one of the most distinguished contributors to liquid crystal science, and real pioneer in their computational study, from Italy if not from the whole world. But the most important lesson I remember from one of these visits does not concern science at all.

One needs to remember that the English are always struggling to get their children into bed. His younger son was then about four years old. The time must have been in the early 1990s. I was staying in Ravenna and we were working late. Suddenly, it must have been about $10 \mathrm{pm}$, the small boy announces that he is tired and is going to bed. Claudio turned with a smile, and with the lightest of light hints, suggested that maybe the English child battles are in vain, for usually children have a good feel for when they need to sleep.

The courtesy in expressing what might be a controversial opinion is an enduring feature of Claudio's relationships, both within and beyond science. It is a stage in life to be 70 . Time was when it was a stage to hang up one's boots and enjoy a quiet retirement. There is, of course, another school of folk thought, that of 'use it or lose it'. Whichever of these life strategies Claudio chooses to follow in the future, or even if it is a linear combination (as we mathematicians say), we wish him luck, good fortune and a long life.

\section{Acknowledgments}

This paper has largely been written within the hallowed historical portals of the Politecnico di Milano. I am grateful to the physicist Paolo Biscari who invited me here, and to the mathematician Stefano Turzi and the chemist Guido Raos with whom I have collaborated in the past and still continue to enjoy fruitful scientific interaction. Many colleagues across Europe, too many to name personally, have first borrowed texts in several different languages from libraries accessible to them and not to me, and then photocopied or scanned them so I would have continuing access. The personal recollections of several colleagues no longer with us, specifically Charles Frank, Jacques Friedel, George Gray and Frank Leslie, have been invaluable in building up a picture of the ongoing field in which we have the privilege to work. Maurice Kléman's 1977 text on Points, Lines and Walls [84] (much fingered, in the original French) has accompanied me across Europe and back, and continues to be an inspiration. Long ago it was Nils Schopohl who persuaded me that he could transfer experience in superconductivity to enable me to think more fruitfully about defects in liquid crystals. 
I owe my interest in Vito Volterra to the historian of science Judith Goodstein. Parts of this article have been extracted (and much edited) from a longer (eventually unpublished) article on Volterra's scientific work originally intended to accompany her magnificent biography of Volterra [24].

Finally, my career in liquid crystals was not originally inspired by Geoffrey Luckhurst, but for almost forty years he has been my closest professional local colleague and my admiration for his continuing skills knows few bounds. It was Geoffrey who brought Claudio Zannoni to Southampton, and through whom I have met an incomparable colleague with innumerable strings to his bow. Finally I thank Claudio himself and the editorial board of 'Liquid Crystals' for doing me the honour of asking me to contribute to this volume. I declare no conflicts of interest, other than those implicit in the paragraphs above. 


\section{References}

[1] T. Sluckin, Professor Sir Charles Frank (1911-1998): Historical perspectives on the development of liquid crystal continuum theory, Liquid Crystals Today 8 (3) (1998) $1-5$.

[2] T. J. Sluckin, D. A. Dunmur, H. Stegemeyer, Crystals that flow: classic papers from the history of liquid crystals, Taylor \& Francis London, 2004.

[3] D. Dunmur, T. Sluckin, Soap, science, and flat-screen TVs: a history of liquid crystals, Oxford University Press, 2011.

[4] G. Friedel, Les états mésomorphes de la matière, in: Annales de Physique, Vol. 9, 1922, pp. 273-474, this famous article is partly translated into English in ref.[ [2]].

[5] G. Volovik, V. Mineev, Line and point singularities in superfluid he-3, Jetp. Lett 24 (1976) 561-563.

[6] M. Kléman, L. Michel, G. Toulouse, Classification of topologically stable defects in ordered media, Journal de Physique Lettres 38 (10) (1977) 195-197.

[7] N. Mermin, The homotopy groups of condensed matter physics, Journal of Mathematical Physics 19 (6) (1978) 1457-1462.

[8] N. D. Mermin, The topological theory of defects in ordered media, Rev. Mod. Phys. 51 (1979) 591-648.

[9] M. Kléman, Defects in liquid crystals, Rep. Prog. Phys. 52 (1989) 555-654.

[10] E. Betti, Sopra gli spazi di un numero qualunque di dimensioni, Annali di Matematica Pura ed Applicata (1867-1897) 4 (1) (1870) 140-158.

[11] J. Stillwell, Mathematics and its History, Springer, 2010.

[12] H. Edelsbrunner, D. Letscher, A. Zomorodian, Topological persistence and simplification, in: Foundations of Computer Science, 2000. Proceedings. 41st Annual Symposium on, IEEE, 2000, pp. 454-463.

[13] P. M. Knoll, H. Kelker, Otto Lehmann: Researcher of the liquid crystals, BoD-Books on Demand, 2012.

[14] S. T. Lagerwall, On some important chapters in the history of liquid crystals, Liquid Crystals 40 (12) (2013) 1698-1729.

[15] M. Mitov, Liquid-crystal science from 1888 to 1922: Building a revolution, ChemPhysChem 15 (7) (2014) 1245-1250.

[16] O. Lehmann, Flüssige Kristalle, Wilhelm Engelmann, 1904.

[17] P. Prinsen, P. van der Schoot, Shape and director-field transformation of tactoids, Physical Review E 68 (2) (2003) 021701.

[18] P. Prinsen, P. van der Schoot, Continuous director-field transformation of nematic tactoids, The European Physical Journal E 13 (1) (2004) 35-41.

[19] C. Zhang, A. Acharya, N. J. Walkington, O. D. Lavrentovich, Computational modelling of tactoid dynamics in chromonic liquid crystals, Liquid Crystals (2017) $1-17$.

[20] T. Machon, G. P. Alexander, Umbilic lines in orientational order, Physical Review X 6 (1) (2016) 011033.

[21] C. M. Viola, La legge degli indici razionali semplici e i cristalli liquidi, Processi verbali di Società Toscana di Scienze naturali (1901) 178-193Read at meeting of 17 March 1901. 
[22] C. W. Oseen, Die anisotropen Flüssigkeiten: Tatsachen und Theorien, Gebrüder Borntraeger, 1929.

[23] A. Guerraggio, G. Paoloni, Vito Volterra, Springer-Verlag, 2010.

[24] J. R. Goodstein, The Volterra Chronicles: The Life and Times of an Extraordinary Mathematician, 1860-1940, American Mathematical Soc., 2007.

[25] J. Weingarten, Sulle superficie di discontinuá nella teoria della elasticità dei corpi solidi, Rendiconti della R. Accademia Lincei 10 (1901) 57-60.

[26] H. Lamb, Hydrodynamics, 2nd Edition, Cambridge University Press, 1895, (An original volume under the title of $A$ treatise on the mathematical theory of the motion of fluids appeared in 1879, while another edition of Hydrodynamics appeared in 1906).

[27] V. Volterra, Sull'equilibrio dei corpi elastici più volte connessi, Rendiconti della R. Accademia Lincei 14 1 (1905) 193-202, (See also other articles in the original series on distorsioni on pp 127-137, pp 350-6, pp 431-8, pp 641-54 and vol 14 2 pp 32942.).

[28] V. Volterra, Sur l'équilibre des corps élastiques multiplement connexes, Annales de l'École Normale Supérieure 24 (1907) 401-518.

[29] V. Volterra and E. Volterra, Sur les distorsions des corps élastiques (théorie et applications), Gauthier-Villars (Paris), 1960, (The first three chapters of this book were written by Volterra père in 1938, and the rest was completed much later by Volterra fils. ).

[30] A. E. H. Love, A treatise on the mathematical theory of elasticity, 1st Edition, Cambridge University Press, 1892, (The 4th edition of Love, published in 1927, is the one which transmuted Volterra's distorsioni into "dislocations").

[31] W. H. Bragg and W. L. Bragg, The reflection of X-rays by crystals, Proc. Roy. Soc. A 88 (1913) 428-38.

[32] P. Knipping, Zehn Jahre Röntgenstrahlinterferenzen, Die Naturwissenschaften 10 (1922) 366-9.

[33] W. H. Brock, D. M. Knight, The atomic debates:" memorable and interesting evenings in the life of the chemical society", Isis 56 (1) (1965) 5-25.

[34] J. Frenkel, Zur Theorie der Elastizitätsgrenze und der Festigkeit kristallinischer Körper, Zeitschrift für Physik 37 (1926) 572-609.

[35] U. Dehlinger, Zur Theorie der Rekristallisation reiner Metalle, Annalen der Physik 2 (1929) 749-793.

[36] G. I. Taylor, The Mechanism of Plastic Deformation of Crystals. part I. Theoretical, Proc. Roy. Soc. A 145 (1934) 362-87.

[37] E. Orowan, Zur Kristallplastizät III: Über die Mechanismus der Gleitvorganges, Zeitschrift für Physik 89 (1934) 634-59.

[38] M. Polanyi, Über ein Art Gitterstörung, die einen Kristall plastisch machen könnte, Zeitschrift für Physik 89 (1934) 660-4.

[39] J. M. Burgers, Some considerations of the field of stress connected with dislocations ina regular crystal latticce, Koninklijke Nederlandse Akademie van Wetenschappen 42 (1939) 293-325 (Part I), 378-399 (Part II).

[40] J. M. Burgers, Geometrical considerations concerning the structural irregularities to be assumed in crystals, Proc. Phys. Soc. (London) 52. 
[41] W. K. Burton, N. Cabrera, F. C. Frank, Role of dislocations in crystal growth, Nature 163 (1949) 398-399.

[42] A.W.C. Menzies and C.A. Sloat, Spiral markings on carborundum crystals, Nature (London) 163 (1929) 348-9.

[43] F. C. Frank, Crystal dislocations.elementary concepts and definitions, Phil. Mag. 42 (331) (1951) 809-819.

[44] J. Friedel, Graine de mandarin, Odile Jacob, 1994.

[45] F. C. Frank, On the theory of liquid crystals, Discussions of the Faraday Society 25 (1958) 19-28.

[46] F. M. Leslie, Some constitutive equations for liquid crystals, Archive for Rational Mechanics and Analysis 28 (4) (1968) 265-283.

[47] Orsay, Liquid, Crystal, Group, Lignes doubles de désinclinaison dans les cristaux liquides cholestériques a grands pas, Journal de Physique Colloques 30 (C4) (1969) C4-38.

[48] M. Kleman, J. Friedel, Lignes de dislocation dans les cholestériques, Le Journal de Physique Colloques 30 (C4) (1969) C4-43.

[49] Y. Bouligand, M. Kléman, Paires de disinclinaisons hélicoïdales dans les cholestériques, Journal de Physique 31 (11-12) (1970) 1041-1054.

[50] T. Bellini, C. Chiccoli, P. Pasini, C. Zannoni, Monte carlo study of liquid-crystal ordering in the independent-pore model of aerogels, Physical Review E 54 (3) (1996) 2647.

[51] T. Bellini, M. Buscaglia, C. Chiccoli, F. Mantegazza, P. Pasini, C. Zannoni, Nematics with quenched disorder: what is left when long range order is disrupted?, Physical Review Letters 85 (5) (2000) 1008.

[52] T. Bellini, M. Buscaglia, C. Chiccoli, F. Mantegazza, P. Pasini, C. Zannoni, Nematics with quenched disorder: how long will it take to heal?, Physical Review Letters 88 (24) (2002) 245506.

[53] M. Rotunno, M. Buscaglia, C. Chiccoli, F. Mantegazza, P. Pasini, T. Bellini, C. Zannoni, Nematics with quenched disorder: pinning out the origin of memory, Physical Review Letters 94 (9) (2005) 097802.

[54] M. Buscaglia, T. Bellini, C. Chiccoli, F. Mantegazza, P. Pasini, M. Rotunno, C. Zannoni, Memory effects in nematics with quenched disorder, Physical Review E 74 (1) (2006) 011706.

[55] D. J. Cleaver, S. Kralj, T. J. Sluckin, M. P. Allen, The random anisotropy nematic spin model, in: G. P. Crawford, S. Zumer (Eds.), Liquid Crystals in Complex Geometries, Taylor \& Francis, 1996, pp. 467-482.

[56] A. Ranjkesh, M. Ambrožič, S. Kralj, T. J. Sluckin, Computational studies of history dependence in nematic liquid crystals in random environments, Physical Review E 89 (2) (2014) 022504.

[57] P.-G. de Gennes, Short range order effects in the isotropic phase of nematics and cholesterics, Molecular Crystals and Liquid Crystals 12 (3) (1971) 193-214.

[58] J. M. Ball, Mathematics and liquid crystals, Molecular Crystals and Liquid Crystals 647 (1) (2017) 1-27.

[59] A. Poniewierski, T. J. Sluckin, On the free energy density of non-uniform nematics, Molecular Physics 55 (5) (1985) 1113-1127. 
[60] L. Longa, D. Monselesan, H.-R. Trebin, An extension of the landau-ginzburg-de gennes theory for liquid crystals, Liquid Crystals 2 (6) (1987) 769-796.

[61] N. Schopohl, T. J. Sluckin, Defect core structure in nematic liquid crystals, Physical review letters 59 (22) (1987) 2582.

[62] P. Biscari, G. Guidone Peroli, T. J. Sluckin, The topological microstructure of defects in nematic liquid crystals, Molecular Crystals and Liquid Crystals Science and Technology. Section A. Molecular Crystals and Liquid Crystals 292 (1) (1997) 91-101.

[63] N. Schopohl, T. J. Sluckin, Hedgehog structure in nematic and magnetic systems, Journal de Physique 49 (7) (1988) 1097-1101.

[64] E. Penzenstadler, H.-R. Trebin, Fine structure of point defects and soliton decay in nematic liquid crystals, Journal de Physique 50 (9) (1989) 1027-1040.

[65] S. Mkaddem, E. Gartland Jr, Fine structure of defects in radial nematic droplets, Physical Review E 62 (5) (2000) 6694.

[66] S. D. Hudson, R. G. Larson, Monte carlo simulation of a disclination core in nematic solutions of rodlike molecules, Physical review letters 70 (19) (1993) 2916.

[67] C. Chiccoli, P. Pasini, F. Semeria, T. Sluckin, C. Zannoni, Monte carlo simulation of the hedgehog defect core in spin systems, Journal de Physique II 5 (3) (1995) $427-436$.

[68] O. D. Lavrentovich, P. Pasini, C. Zannoni, S. Zumer, Defects in liquid crystals: Computer simulations, theory and experiments, Kluwer Academic Publishers, 2001, vol 43 of NATO Science Series in Mathematics, Physics and Chemistry.

[69] C. Chiccoli, P. Pasini, I. Feruli, C. Zannoni, Computer simulations and defects in confined liquid crystal lattice models, in: Defects in Liquid Crystals: Computer Simulations, Theory and Experiments, Springer, 2001, pp. 87-112.

[70] M. Kleman, O. D. Lavrentovich, Topological point defects in nematic liquid crystals, Philosophical Magazine 86 (25-26) (2006) 4117-4137.

[71] C. Chiccoli, I. Feruli, O. Lavrentovich, P. Pasini, S. V. Shiyanovskii, C. Zannoni, Topological defects in schlieren textures of biaxial and uniaxial nematics, Physical Review E 66 (3) (2002) 030701.

[72] C. Chiccoli, P. Pasini, I. Feruli, C. Zannoni, Simulations of topological defects in nematic liquid crystal films, Molecular Crystals and Liquid Crystals 398 (1) (2003) 195-206.

[73] M. A. Bates, G. Skačej, C. Zannoni, Defects and ordering in nematic coatings on uniaxial and biaxial colloids, Soft Matter 6 (3) (2010) 655-663.

[74] C. Chiccoli, P. Pasini, L. R. Evangelista, R. Teixeira de Souza, C. Zannoni, Lattice spin simulations of topological defects in nematic films with hybrid surface alignments, International Journal of Modern Physics C 22 (05) (2011) 505-516.

[75] D. Vanzo, M. Ricci, R. Berardi, C. Zannoni, Shape, chirality and internal order of freely suspended nematic nanodroplets, Soft Matter 8 (47) (2012) 11790-11800.

[76] G. R. Luckhurst, T. J. Sluckin, Biaxial nematic liquid crystals: theory, simulation and experiment, John Wiley \& Sons, 2015.

[77] C. Chiccoli, L. Evangelista, P. Pasini, G. Skačej, R. T. de Souza, C. Zannoni, On the defect structure of biaxial nematic droplets, Scientific reports 8 (1) (2018) 2130. 
[78] J. D. Weeks, D. Chandler, H. C. Andersen, Role of repulsive forces in determining the equilibrium structure of simple liquids, Journal of Chemical Physics 54 (12) (1971) 5237-5247.

[79] L. S. Ornstein, F. Zernike, Accidental deviations of density and opalescence at the critical point of a single substance, Proceedings of the Royal Netherlands Academy of Arts and Sciences 17 (1914) 793-806, english version available from http://www.dwc.knaw.nl/DL/publications/PU00012727.pdf.

[80] P. G. de Gennes, J. Prost, The Physics of Liquid Crystals, 2nd Edition, Clarendon Press, Oxford, 1993, it is the 1974 first edition by de Gennes alone to which I am referring, rather than this jointly authored version.

[81] G. R. Luckhurst, G. W. Gray, The Molecular Physics of Liquid Crystals, Academic Press, 1979.

[82] C. Zannoni, Distribution functions and order parameters, in: G. R. Luckhurst, G. W. Gray (Eds.), The molecular physics of liquid crystals, Academic Press, London, 1979, Ch. 3, pp. 51-83.

[83] F. C. Frank, Quasi-kristalline und kristalline flussigkeiten, Physikalische Zeitschrift 39 (1939) 530-534.

[84] M. Kléman, Points, lignes, parois, Éd. de Physique, 1978. 